\title{
Kdo se boji disleksije?
}

\author{
Dušana Findeisen
}

\begin{abstract}
Pismenost in numeričnost povečata vse naše druge sposobnosti. Osebe s posebnimi učnimi težavami ali z disleksijo, pri katerih sta pismenost in numeričnost lahko prizadeti, se učijo drugače. Disleksija lahko prizadene njihovo samozavest, omejuje izobraževanje, poklicno delo, druženje $z$ drugimi in njihove vsakodnevne dejavnosti.
\end{abstract}

Večina otrok si pridobi pismenost in numeričnost $v$ šoli. Bistrejši otroci to dosežejo hitreje kot manj bistri. Toda, kaj storiti z otrokom, ki je bister, toda le počasi in slabo napreduje pri teh pomembnih osnovnih spretnostih? Ali so ti otroci nekaj posebnega in ali jih je mogoče ločiti od tistih, ki nimajo posebnih, marveč splošne učne težave? Če otrok v šoli ne napreduje zaradi okolja, v katerem živi, če nima dosti možnosti za učenje, dovolj spodbud, podpore ali dobrega učitelja, bo s primerno pomočjo hitro napredoval. Če pa vzroki za neuspeh izhajajo iz otroka samega, najverjetneje ne bo napredoval bolj kot drugi učenci s splošnimi učnimi težavami.

Lahko trdimo, da je disleksija pri posameznikih različna glede na vzroke, napovedi, odzivanje na pomoč strokovnjakov in drugih, pa tudi glede na življenjsko obdobje. In vendar moramo vedeti, da se značilnosti disleksije ohranijo tudi pri odraslih, da prizadevajo tudi odraslega človeka in ga omejujejo pri njegovi uspešnosti. Toda tudi stanje odraslega disleksika se lahko izboljša, če se ta $\mathrm{z}$ disleksijo sprijazni. Število odraslih disleksikov ni majhno. Britanske raziskave so na primer pokazale, da je med trajno nezaposljivimi ljudmi vsaj 20 odstotkov disleksikov.

\section{Izpoved disleksikn}

Ste morda tudi vi imeli težave $\mathrm{z}$ notno lestvico in niste doumeli povezave med notnimi simboli in tonom, za katerega je učitelj želel, da ga zapojete? Ste morda tonsko lestvico spremenili v nekakšno pesmico? Morda tudi vi niste mogli razumeti, kar tako po posluhu, da ima beseda mama dva zloga: ma-ma? »Kako to, da ne razumeš, saj je tako preprosto? « so vam morda govorili obupani starši in morebiti je v obojestranski vznemirjenosti in frustriranosti priletela tudi kakšna klofuta. Mnogo kasneje ste morda sami našli pot do razumevanja zlogov. Spoznali ste, da je zlog sestavljen iz soglasnikov, ki se povežejo s samoglasnikom, v slovenskem jeziku tudi s soglasnikom r, ki ima samoglasniško vlogo. To pa je bila analitična, intelektualna in vsekakor daljša pot razumevanja. Ste morda tudi vi med tistimi, ki ne morejo reševati sestavljenk, ker ne ugotovijo manjkajočega dela podobe? Vam je morda kdaj, še v šolskem obdobju, kakšen psiholog dejal: »Glede na tvoje sposobnosti razmišljanja bodo rezultati pri inteligenčnem testu gotovo zelo dobri, « potem pa se vam ni upal povedati poraznih rezultatov, ki ste jih dosegli pri testu, pri katerem je bilo treba posamezne elemente postaviti v logično zaporedje, vi pa teh zaporedij niste ugotovili. Značilnost disleksije je tudi v tem, da se intelektualne sposobnosti disleksika in dejanski rezultati ter opravljene naloge zelo razhajajo, še posebej, kadar so pri takšni nalogi potrebni dobra vizualna zaznava, ugotavljanje zaporedij, uporaba spomina, osredotočenost na misli drugih. Ste imeli morda tudi vi težave s poštevanko? »Trikrat sedem je enaindvajset, štirikrat sedem je osemindvajset, petkrat sedem...« Se je morda tudi vam zataknilo zmeraj na istem mestu ali kar na več mestih?
Poštevanka je oblika zaporedja in učenje zaporedij je pri disleksiku počasnejše. Pri tem seveda ne gre le za poštevanko. Zaporedje je tudi organizacija diskurza, pri čemer je potrebna diskurzna kompetenca in tudi ta je pri disleksiku prizadeta. Ko ste se znašli na prvem računalniškem tečaju, vas je mentor računalničar postavil pred ekran in vas zasul s kakimi desetimi navodili hkrati, vendar ste ga slišali le še do drugega navodila, potem pa ste zgubili nit. Vsi drugi tečajniki so imeli manj težav kot vi. » To bi morali obvladati že včeraj!« je morda tudi vam dejal mentor. Se vam včasih v novih okoliščinah zazdi, da napeto in z naporom poslušate sogovornika, v strahu, da ga ne boste razumeli? In res se vam zdi, da vam misli blodijo, zato vas kaj kmalu od napora začne boleti glava. Se vam na mednarodnih konferencah, kjer je marsikaj novega, vse polno obrazov in imen, imen institucij itd., zazdi, da bi najraje pobegnili, ker si ničesar ne morete zapomniti? Se včasih bojite spregovoriti v strahu, da se ne bi mogli izraziti, da se bodo $\mathrm{v}$ vas zazrli pogledi drugih ljudi, $\mathrm{v}$ katerih boste videli nerazumevanje? Ne nestrinjanje, marveč nelagodnost nerazumevanja. Svoj govor morda s težavo organizirate v logično celoto. Imate veliko notranjih misli, ki so sicer urejene logično, vendar je to notranja logika, ki je drugi niti ne slutijo. In ker ne morejo biti priče tej vaši notranji organizaciji diskurza in so deležni le nekaterih vmesnih misli, tistih, ki jih spregovorite, ne da bi vedeli, da so bile predhodne misli le $\mathrm{v}$ vas samih. Kadar pišete, imate vse polno izvirnih zamisli, vendar poleg poglavitne misli brbotajo podmisli, stranpoti, le $\mathrm{z}$ velikim naporom in dolgotrajno vajo se obdržite na vajetih in nekako organizirate svoj diskurz tako, da je za druge sporočilen. Se bojite, da se vam bo občasno misel povsem pretrgala? Se vam pred predavanjem zdi, da ničesar ne znate in da ne boste mogli študentom prav ničesar povedati, čeprav ste dneve in dneve razmišljali in se pripravljali ter imate vse polno izvirnih zaznav in misli? Se vam je kdaj zgodilo, da so vas prijatelji čudno gledali, ker kljub naporu niste mogli dobro razbrati na zemljevi$\mathrm{du}$, kod se vozite in koliko kilometrov je do naslednjega kraja? Zdaj, ko ste odrasli, in če ste imeli srečo, da vas šola in starši niso zatrli, ste si poiskali svoje, za druge nenavadne in izvirne poti razumevanja in reševanja problemov. Tudi svoje vizualno zaznavanje ste izboljšali, tako da si posebej zapomnite vsak posamezen element razgibane risbe ali slike in si ga morda $\mathrm{z}$ besedami opišete tako, da iz spomina nekako izvlečete celo sliko, kadar je treba. S težavo, vendar vam le uspe. Miselni vzorci so za vas še zmeraj nekaj groznega, saj si niste zmožni zapomniti več kot dva mehurčka. Z grafikoni in diagrami je že lažje.

Poskušala sem našteti nekaj svojih težav pri zaznavanju, povezovanju in izražanju. V stroki jih imenujejo »posebne učne težave« ali disleksija. Včasih uporabljamo tudi besedno zvezo »besedna slepota«. Disleksijo povezujejo pogosto tudi $\mathrm{z}$ raznimi oblikami afazije, to je motenj pri oblikovanju mišljenja in govora. V raznih oblikah je pogosta pri epileptikih. Moje težave niso 
izrazite in zdi se mi, da jih med mojim dolgotrajnim šolanjem ni nihče zares odkril. Zdi se, da sem tudi sama odkrila mnogo načinov, da sem te težave bolj ali manj dobro prikrila. Šolanje v tujini mi je pomagalo, da sem morebitne napake skrila za nedovoljšnjim poznavanjem francoskega jezika. Večina izpitov je bila takšnih, da ni šlo za reproduciranje znanja in podatkov, marveč za razmišljanje o dani temi ali vprašanju, pogosto tudi za komentar posameznega besedila. Profesorje je večinoma presenečala izvirnost mojega mišljenja, ki so jo verjetno pripisovali poglobljenemu brskanju po virih, tujemu poreklu in ustvarjalnemu mišljenju. Ko sem se vrnila v domače okolje, pa je bilo moje mišljenje tako zaznamovano s svojevrstnim pogledom na svet, ki je značilen za Francoze, da se je moje razmišljanje zdelo zaradi daljše izpostavljenosti francoski kulturi nenavadno in včasih težje razumljivo. Za vsem tem sem nekako varovala svojo samopodobo. Sicer pa je disleksik včasih sposoben nenavadnih in hitrih miselnih asociacij in tudi to me je reševalo. Če se dobro počutim, potem so te hitre asociacije za okolje lahko duhovite, če pa nisem razpoložena, potem sem tiho in se bojim spregovoriti.

Zanimivo je, da ima večina disleksikov sicer težave pri učenju tujih jezikov, jaz pa sem zmeraj misel lažje organizirala v tujem kot v domačem jeziku. Morda bi to lahko pripisali dejstvu, da se v naših možganih ustvarijo ločena središča za posamezne jezike. Pravzaprav je to le ugibanje, kajti nevrološkega znanja nimam prav dosti. Pri obravnavanju disleksije pa si moramo takšno znanje pridobiti. Pa ne zgolj nevrološko! Tudi znanje iz psihologije, lingvistike, pedagogike, andragogike in didaktike potrebujemo.

\section{Opredelifev disleksije}

Psihološka obravnava učenja in razvoja, ki se osredotoči na učni proces in izdelke, psihoizobraževalna obravnava, ki se posveti pedagogiki, in medicinska obravnava, ki vprašanje obravnava kot bolezen, ki jo je treba zdraviti, nedvomno privedejo do nasprotujočih si interpretacij nekaterih (ne pa tudi vseh!) težav s pismenostjo. Ena od delovnih opredelitev disleksije je, da je »... disleksija ... težava, zaradi katere otroci po običajnih učnih poteh niso uspešni pri branju, pisanju in črkovanju, kar se ne ujema $\mathrm{z}$ njihovimi siceršnjimi intelektualnimi sposobnostmi.« (Critchley, 1970) Strokovnjaki ločujejo tudi med razvojno in pridobljeno disleksijo. Do te pride zaradi poškodb centralnega živčnega sistema, infekcije itd.

Ameriški psihiater Orton je odkril, da imajo disleksični otroci posebne težave s tiskanimi simboli, še posebej s tistimi črkami in besedami, ki jih je mogoče zamenjati, kot so b/d, p/q itd., zato je začel razmišljati, da je disleksija pogosto posledica vizualnih in zaznavnih težav. Zdi se, da je pri disleksiji motena obdelava vizualnih zaznav. Prav tako velja, da ostanejo vizualne zaznave $\mathrm{v} »$ ikonskem« spominu disleksičnih oseb približno 50 odstotkov dlje. Zato disleksične osebe potrebujejo več časa, da preidejo k naslednji fazi vizualne obdelave informacije. To se pokaže pri branju, pri katerem mora oseba ponotranjiti zaporedne delce informacije, to je enega za drugim, največkrat prihaja do težav in počasnosti.

Število opredelitev disleksije je tako veliko (38), da nedvomno samo po sebi izraža pojavno raznolikost. Ker se sama prištevam med disleksike, sem med njimi poiskala tisto, ki najbolje povzema moje težave. »Otrok z učnimi težavami ... ima svojske pomanjkljivosti kar zadeva zaznavne, povezovalne ali izrazne procese, zaradi katerih je njegova učna sposobnost prizadeta.« V opredelitvi je omenjen otrok, in ne odrasla oseba, čeprav se disleksija nadaljuje tudi po otroštvu. Res pa je, da takšen otrok ali odrasla oseba išče svoje in posebne učne poti, postopno jih navadno tudi odkrije, če se mu šola in okolje ne postavita po robu in ga ne prizadeneta. Torej, kadar skušamo pomagati funkcionalno ne-

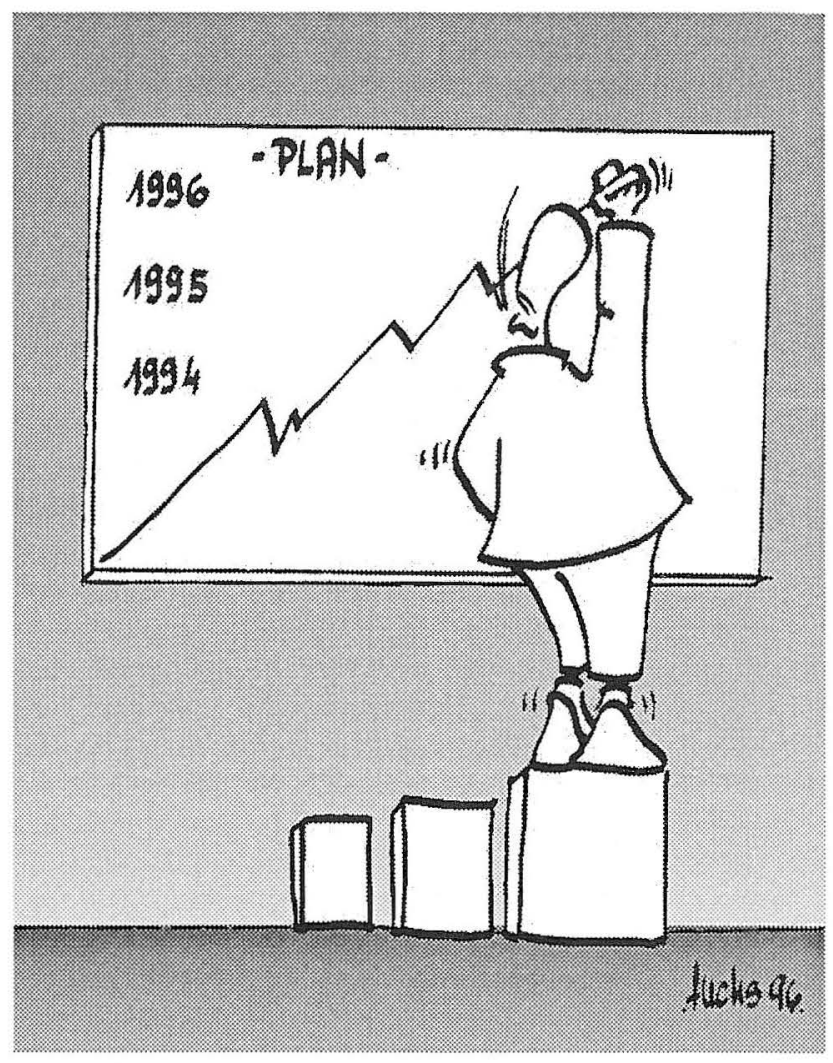

pismenim osebam, poskušamo ugotoviti, če ne gre pri njih morda tudi za takšno ali drugačno obliko disleksije, zaradi katere imajo negativen odnos do izobraževanja.

\section{Prepoznavanje disleksije in ocenjevanje disleksičnosti}

Večina strokovnjakov, ki se ukvarjajo z disleksijo, verjame, da sta zgodnje prepoznavanje in ocena disleksičnosti izredno pomembna. Disleksijo bi morali ugotavljati že vzgojitelji v vrtcih, vendar morajo biti za to posebej izobraženi. Pri tem je pomembno ugotoviti, ali je v otrokovi družini kakšen disleksik, pa tudi to, kako je potekal porod, ali so se morda pri otroku pojavile zgodnje govorne ali jezikovne težave. Si težko zapomni stvari? Ima morda težave $\mathrm{z}$ rimo, aliteracijo in govorno težko izrazi svoje težave? Ali mu ločevanje med levo in desno stranjo povzroča težave? Ima morda slab slušni spomin za zaporedja, tako da si na primer težko zapomni zaporedje dnevov, mesecev ali zaporedje črk $\mathrm{v}$ abecedi? Ko sem sama opazovala fanta s frontalno epilepsijo in mu pomagala pri pripravah na radioamaterski izpit, sem lahko videla, kako se je moral truditi, da si je zapomnil poimenovanja črk. Ko bi moral to storiti še v angleškem jeziku, pa se je dokončno uprl. Obvladovanje zaporedja in poimenovanje simbolov sta pri disleksikih težavna.

Če ima otrok na začetku šolanja težave pri branju, pisanju in črkovanju, moramo biti na to pozorni, čeprav takrat še ni mogoče natančno ugotoviti vzrokov za te težave. Zato je treba navedene sposobnosti takrat tudi testirati.

Disleksike moramo celostno oceniti, da ugotovimo in dokažemo:

- njihovo stopnjo razumevanja govornega in pisnega jezika ter besedni zaklad;

- njihovo stopnjo spretnosti branja in črkovanja v povezavi z njihovimi splošnimi sposobnostmi;

- njihove bralne metode in načine, kako se naučijo črkovati; 
- sposobnost za delo s številkami;

- sposobnost pisanja posameznih odstavkov;

- njihov kognitivni profil na podlagi standardiziranih testov;

- njihove spretnosti poslušanja in oblikovanja glasov;

- vizualno-motorične zaznavne sposobnosti, še posebej je treba ugotoviti, ali jim pri branju morda pogled ne uhaja $\mathrm{z}$ leve proti desni in če sta pogled in roka usklajena;

- njihov besedni in vizualni spomin.

Nekatera področja, na katerih je otrok slabši, bolj kot druga kažejo na to, da ne gre za posplošeno obliko učnih težav, marveč za posebne učne težave. Te so včasih le izraz otrokovih čustvenih težav. Čustvene težave in moteno vedenje so lahko tudi posledica posebnih učnih težav oziroma disleksije ali pa kaže vse te težave pripisati nečemu drugemu. In vendar, kot sem dejala, težave na nekaterih področjih kažejo, da gre najverjetneje za disleksijo. Ti posebni indikatorji disleksije pa so:

- zastalost govornega in jezikovnega razvoja;

- mešanje vrstnega reda besed;

- slabo ločevanje leve in desne strani;

- slab slušni spomin;

- težavna organizacija diskurza;

- čudno črkovanje;

- zamenjavanje črk b/d ali d/t;

- preobračanje črk na glavo;

- zrcalno pisanje;

- slab vizualni spomin;

- nerodnost;

- slaba koncentracija.

Na začetku ocenjevanja je treba torej natančno poznati razvoj otrokovih učnih težav. Natančna ocena nam bo odkrila, kako otrok ravna, se odziva. Na tej podlagi nato načrtujemo pomoč pri otrokovem učenju.

Tudi s psihološkega vidika sta pomembna prepoznavanje in ocena disleksičnosti. Če otroku in staršem primerno razložijo disleksične težave, se otrokovo življenje največkrat takoj spremeni. Če so ga prej imeli za lenega, trmastega ali neumnega, zdaj vedo, da se otrok tako odziva na disleksijo. Vzroke otrokovega vedenja tako spoznajo tudi strokovnjaki, ki delajo z njim. Pomembno pa je tudi, da učiteljem in staršem svetujejo o poučevanju otroka.

Psihologi se morajo posvetiti delu z učitelji. Primerno izobraženi učitelji, pa tudi primerno usposobljeni, se lahko naloge, ki jo imajo pred seboj, učinkovito lotijo. Učitelji morajo sodelovati s psihologi. Še več, posvetiti morajo pozornost vsemu, kar vpliva na otrokovo učenje: kulturnim, okoljskim in osebnostnim dejavnikom, ki vplivajo na testne rezultate. Ocena disleksičnosti je potrebna tudi za izpitne komisije, ki se na tej podlagi odločijo, katero vrsto preizkusov bodo uvedle za kandidate. Če bi namreč večina ocenjevanja potekala ustno in bi bilo tudi učenje predvsem ustno, bi mnogi disleksični otroci dosegali boljše rezultate.

\section{Pomor̆ disleksikom}

Disleksiki se uvrščajo med tiste posameznike, ki imajo posebne izobraževalne potrebe. V nekaterih evropskih državah (in tudi pri nas) so se tega lotili najprej tako, da so za vse otroke organizirali dopolnilno izobraževanje. Takšen dopolnilni pouk pomeni, da se ga otroci ne udeležujejo skupaj z drugimi učenci in da poteka zunaj rednih ur. V nekaterih državah, še posebej v Veliki Britaniji, obstajajo posebni razredi za disleksične učence ali pa disleksični otroci obiskujejo poseben center, kjer imajo specializiran dopolnilni pouk. Vendarle takšno ločevanje otrok ni najbolj priporočljivo, niti za učence niti za učitelje, ki tako večinoma delajo le z disleksičnimi otroki in zgubijo stik s kolegi, ki poučujejo $\mathrm{v} »$ normalnih« razredih.

Primernejša oblika pomoč in podpora disleksikom je morda v običajnem razredu. Pouk je mogoče organizirati tako, da skupaj poučujeta dva učitelja, pri čemer tisti, ki je specializiran za disleksijo, vodi skupino, v kateri je en disleksičen učenec ali pa jih je več, in temu primerno priredi metode poučevanja. Skrbno opazuje učenca, saj je takšno opazovanje podlaga za pripravo drugačnega učnega načrta. Še več, za otroke s posebnimi učnimi težavami je mogoče zagotoviti:

- posebej pripravljene in oblikovane delovne liste;

- razlago navodil ;

- kaseto, na kateri je posnet seznam literature;

- fotokopijo zapiskov, da učencu ni treba hitro zapisovati;

- možnost snemanja zapiskov ali besedila;

- učiteljevo prisotnost in njegovo pomoč, predvsem takrat, ko učenec prepisuje zapiske s posnetka;

- urejevalnik besedila za daljša pisna dela;

- pouk za učinkovito uporabo urejevalnika besedil;

- poučevanje učinkovite organizacije učenja;

- dopolnilni program za specifične težave.

Pri tem je seveda pomemben učitelj, ki si mora pridobiti dodatno znanje in spretnosti. Dovolj dobro mora poznati zakonitosti in načela učenja, da jih lahko prilagodi disleksičnim učencem. Tako imajo ti dostop do celotnega učnega programa. Disleksičnim učencem pa bodo koristili predvsem ustni učni načini, pa tudi to, da se jim ne bo treba sporazumevati pisno. ${ }^{1}$

\section{Sklepne misli}

Za uspešno odpravljanje disleksije je treba uvesti v šole, območne skupnosti za zaposlovanje in v slovensko vojsko službe ali strokovnjake za prepoznavanje in ocenjevanje zgodnejše disleksije. Čim zgodnejše je takšno prepoznavanje in ocenjevanje, tem manj bo prizadeta disleksikova samopodoba in učinkovitejše bo njegovo učenje. Seveda kaže v zvezi s tem razmisliti tudi o izobraževanju učiteljev, ki bi morali znati upoštevati drugačnost učnih potreb. In sicer takrat, kadar gre za otroke, in tudi takrat, kadar gre za disleksijo pri odraslem človeku. Disleksija bi morala biti opredeljena tudi v šolski zakonodaji, saj sta pismenost in numeričnost kot oblika simbolnega mišljenja v zahodnih civilizacijah izjemno pomembni. Dostopni morata biti vsem, tudi disleksikom.

\section{Dušana Findeisen}

Logos - jezikovno izobraževanje, skupina samostojnih izobraževalcev

\section{Liferature}

Critchley, M. (1970) : The Dyslexic Child. London: Heinemann.

Orton, S. T.: (1937) : Reading, Writing and Speech Problems in Children. New York, Norton.

Pumfrey, P. D.(1995): Specific Learning Difficulties, London, Routledge.

Vygotski, L. : (1962): Thought and Language, Cambridge, MIT Press.

${ }^{1}$ Zvočna knjižnica Zveze slepih in slabovidnih Slovenije zaradi zapletov $\mathrm{z}$ avtorskimi pravicami ni javna knjižnica. Dostopna bi morala biti tudi drugim, med drugim disleksičnim osebam. Te bi morale imeti tudi pravico do drugačnega poučevanja in ustnega preverjanja znanja. 